\title{
IMPROVEMENT OF THE SYSTEM OF MANAGEMENT OF PROFESSIONAL DEVELOPMENT OF PERSONNEL: THE CASE OF UKRAINE
}

\author{
Serhii Makarenko', Nataliia Oliinyk2², Yana Oleksenko³
}

\begin{abstract}
Theoretical and methodical aspects of rating performance appraisal of sci-entific and pedagogical workers of educational institutions are object of research. The purpose of the article is to study the factors of influence and provide recommendations for improving the system of management of professional development of personnel of educational institutions. The results are obtained through the use of methods: expert method is used to identify the impact of qualitative and quantitative indicators on the efficiency of use of labor resources; economic and mathematical method is performed to determine the integral indicator of the assessment of the efficiency of the use of labor resources; abstract-logical method is executed for theoretical generalization and formulation of conclusions. It has been revealed that the lack of a sound methodological approach to employee rating and appropriate means of motivation for professional development can lead to the loss of existing intellectual potential and competitive positions of educational institutions in the market of educational services in general. It has been found that in order to introduce an effective model of personnel management in educational institutions, it is very important to provide the main criteria for evaluating its effectiveness at the stage of formation. It was found that special attention should be paid to development of substantiated scientific and methodological approaches to the assessment of professional qualifications level of employees in the testing group and in the dynamics, determining the limit load and development model of a motivation model for professional development. When assessing the level of professional qualification of teaching staff, it is proposed to take into account not only their own property to scientific and pedagogical industry, but also the results of their pupils' work. In determining the integral indicator of the assessment of the efficiency of the use of labor resources, the method of taxonomic analysis was used with additional consideration of the specific weight of influence of each factor on an integral indicator. It is substantiated that the definition of the boundary load will not only establish an effective bonus system, but also increase the level of job satisfaction among subordinates. The mechanism of determining the coefficient of competence of experts involved in the evaluation of staff, taking into account their work experience, the scale of management activity, and the level of education, deserves further study.
\end{abstract}

Key words: management, educational institution, labor resources, professional development, integral indicator.

JEL Classification: M12, M54

\section{Introduction}

Today's conditions of constant growth of the level of competition between educational institutions are the key part of success for the permanent increase of professional competences of pedagogical and scientific and pedagogical employees as a basis for providing qualitative educational services.

\footnotetext{
Corresponding author:

${ }^{1}$ Kherson State University, Ukraine.

E-mail: makar0684@gmail.com

ORCID: http://orcid.org/0000-0001-9929-8967

ResearcherID: https://publons.com/researcher/1878529/serhii-makarenko/

${ }^{2}$ Kherson National Technical University, Ukraine.

E-mail: nat-o@ukr.net

ORCID: http://orcid.org/0000-0002-1019-5708

${ }^{3}$ Kherson State University, Ukraine.

E-mail: yanochka.oleksenko@gmail.com

ORCID: http://orcid.org/0000-0003-4954-0545
}

Research and solutions of current problems, which constraint the staff devel-opment, are one of the most urgent tasks not only for the management of educational institutions, but also for society as a whole. Modern economic and social situation in Ukraine has not only dramatically changed the ideas and values, but also has given rise to an uncertain, very often groundlessness, 
attitude to many values and norms, including the needs for a constant personal development. The most important component of the professional development of staff became the superficial material aspect, according to which the employee is engaged, the improvement of professional skills only in case of urgent need for retention in a position of employment or as component to increase the amount of pay work in the short term perspective. And that is not taking into account the fact that the most important part of professional development is the intellectual personal development and additional professional competencies. Only because of the necessary qualification level of pedagogical and scientific and pedagogical worker, he or she will be able to realize himself or herself on labor market as a successful specialist and get a decent salary in budget and private spheres of economic activity in the future.

The results of the research conducted by Redko S., Panchenko A. (2015) show that a significant amount of intangible motivation that leaders of educational institutions have used in the past (awarding certificates, audits, etc.), do not bring the desired changes in significant numbers of teachers today. And if they lead to change, then these changes have a short duration. Therefore, the head of the school has to constantly look for new opportunities to intensify the process of improvement of teaching staff, first of all, at the expense of the internal resources of your institution, and build a dynamic and flexible system of motivation of teaching staff on the basis of research peculiarities of their motivational sphere.

According to Mokin B. I., Marymonchyk Yu. V. (2004), an effective system of stimulating teaching staff provide the encouragement preparation of highly quali-fied scientific and pedagogical staff (motivation of relations) and achievement of scientific works of various way (process orientation) in the form of a salary supplement.

Obmok O. H. (2014) proposes to use the rating of results of the work of teaching staff as an element of their motivation to high-performance activities that enhance the collective interest of scientific and pedagogical staff to improve the final results of institutions activities of higher education, obtaining higher positions in intercollegiate ratings.

Despite the considerable experience, there are questions that need to be addressed to additional scientific analysis, especially with regard to improve the man-agement system for professional development of personality. Every head of an educational institution, who is striving to ensure effective functioning in the short and long term prospect, must constantly explain the need for permanent improvement, but some additional measures aimed on encouraging the employees to update their knowledge and improve it professional competence are also required. This is especially true in today's context of financial and other material resources, insufficient financing of expenses for the maintenance of pedagogical and scientific pedagogical staff. The above is determined by the relevance of the research topic, its tasks and content.

The purpose of the article is to study the factors of influence and provide recommendations for improving the system of management of professional development of personnel of educational institutions.

\section{Research methodology}

The methodological basis of the research was made by the scientific works of domestic, foreign scientists and leading experts, statistical and analytical materials of public authorities. As a method of data collection for the research the questionnaire was chosen. The survey was conducted among top executives of educational institutions (Kherson State University, School of Liberal Arts), local state executive bodies (Department of Economic and Regional Development of Kherson Regional State Administration), Kherson Regional Intersectoral Council of Trade Unions. The results are obtained through the use of methods: expert method is used to identify the impact of qualitative and quantitative indicators on the efficiency of use of labor resources; economic and mathematical method is performed to determine the integral indicator of the assessment of the efficiency of the use of labor resources; abstract-logical method is executed for theoretical generalization and formulation of conclusions.

The following formula was used to transfrom a particular set of indicators with different units of measurement into a single scale of evaluation (Tyukhtenko, Makarenko, 2016):

$$
\text { - } \mathrm{K}_{\mathrm{j}}=\sum_{\mathrm{i}=1}^{\mathrm{n}} \frac{\mathrm{X}_{\max }-\mathrm{X}_{\mathrm{ij}}}{\mathrm{X}_{\max }-\mathrm{X}_{\min }}+\sum_{\mathrm{i}=1}^{\mathrm{n}} \frac{\mathrm{X}_{\mathrm{ij}}-\mathrm{X}_{\min }}{\mathrm{X}_{\max }-\mathrm{X}_{\min }},
$$

where $K_{j}$ - the coefficient for each of the indicators characterizing a particular component of activity;

$X_{i j}$ - the value of the $i$-th indicator of the $j$-th group

$\mathrm{X}_{\max }$ - the maximum value of the $\mathrm{i}$-th indicator in the middle of the testing group;

$\mathrm{X}_{\min }$ - the minimum value of the $\mathrm{i}$-th indicator in the middle of the examined group.

The first part of the formula is used to evaluate indicators, the growth of which has a positive impact, the second part is to evaluate indicators, the increase of which has a negative effect (e.g., number of conflicts, number of absences, etc.).

The best is the classroom, the arithmetic mean of the sum of the ratings of which is the lowest.

To determine the integral indicator of labor resources competitiveness, the method of taxonomic analysis was used, with additional consideration of the specific impact of each factor on the integral indicator of labor resources competitiveness. This method is to perform 
the calculation of the integral evaluation in several stages (Makarenko, Oliinyk, Danko, Kaplina, 2020):

Stage 1 - formation of the system of information space of evaluation - matrix of initial data $X=\left(x_{i j}\right)$.

Stage 2 - formation of a matrix of standardized values of attributes by changing the matrix $X$ to the matrix $Z$. The elements of the matrix $Z$ are calculated by the formula:

$$
Z_{i j}=\frac{x_{i j}-x_{a v . j}}{\delta_{j}},
$$

where $x_{a v j}$ - the average value of the $j$-th indicator;

$\delta_{j}-$ rms deviation of $j$-th index.

Stage 3 - formation of "point-standard" with coordinates $\mathrm{Z}_{01}, \mathrm{Z}_{02}, \ldots, \mathrm{Z}_{0 \mathrm{n}}$.

Stage 4 - Euclidean distance $\left(C_{i 0}\right)$ calculation by the formula:

$$
\mathrm{C}_{\mathrm{i} 0}=\sqrt{\mathrm{P}_{\mathrm{j}}^{*} \sum_{\mathrm{j}=1}^{\mathrm{n}}\left(\mathrm{Z}_{\mathrm{ij}}-\mathrm{Z}_{0 \mathrm{j}}\right)^{2}},
$$

where $P_{j}$ - the share of the impact of the $j$-th indicator of labor resources com-petitiveness index.

The distances obtained are the initial values used in the calculation of the inte-gral index.

Stage 5 - calculation of values of integral index $\left(d_{i}\right)$ using the formulas:

$$
\mathrm{d}_{\mathrm{i}}=1-\frac{\mathrm{C}_{\mathrm{i} 0}}{\mathrm{C}_{0}},
$$

where

$$
\begin{aligned}
& \mathrm{C}_{0}=\mathrm{C}_{\mathrm{av} .0}+2 * \mathrm{~S}_{0}, \\
& \mathrm{C}_{\mathrm{av} .0}=\frac{1}{\mathrm{~m}} * \sum_{\mathrm{i}=1}^{\mathrm{m}} \mathrm{C}_{\mathrm{i} 0}, \\
& \mathrm{~S}_{\mathrm{o}}=\sqrt{\frac{1}{\mathrm{~m}} \sum_{\mathrm{i}=1}^{\mathrm{m}}\left(\mathrm{C}_{\mathrm{i} 0}-\mathrm{C}_{\mathrm{av} .0}\right)^{2}},
\end{aligned}
$$

In determining the specific impact of the $j$-th indicator on the integral indicator of the competitiveness of labor resources, a survey was conducted among certain in-stitutions of higher education, local government bodies and trade union organizations. Given that each of the experts involved in the survey has a different level of qualifications, it was suggested to use the methodological approaches developed by the authors (Tyukhtenko, Makarenko, 2016; Makarenko, Oliinyk, Kazakova, 2018) with additional consideration of the level of fluctuations of the corresponding qualification competences in the middle of the testing group.

\section{Features comprehensive evaluation of the results of the testing group}

Professional activity of pedagogical and scientific and pedagogical staff has its own specifics that are directly displayed in the management system of professional development of the personality. One of the basic conditions of increasing the competitiveness of educational institutions is improving the quality of education provided the educational services by ensuring the continuous updating of staff knowledge in an unstable business environment. Improvement of the management system of professional development of pedagogical and scientific and pedagogical staff should take into account the modern aspects of the functioning of educational institutions and realize the potential of staff in the relevant market of segment services. Special attention should be paid to the development of substantiated scientific and methodological approaches to the assessment of professional qualifications level of staff in the testing group and in the dynamics, determining the capacity limit and development a motivation model for professional development.

When assessing the level of professional qualification of teaching staff, it is necessary to consider not only their own property in the scientific and pedagogical branch, but the results of their ward pupils' work. This is especially true when as-sessing the effectiveness of the teaching staff who is also the form master at the part-time.

The methodological approach introduced by the School of Liberal Arts (Kherson, Ukraine) is noteworthy; it is determined by the total efficiency of each educational class within each quarter. This approach assumes summation of points results by 12 groups of indicators: image of the class $\left(A_{1}\right)$; lack of the school uniforms $\left(A_{2}\right)$; sanitary condition of the class $\left(A_{3}\right)$; delay $\left(A_{4}\right)$; faster, higher, stronger $\left(A_{5}\right)$; educational achievements, competitions $\left(\mathrm{A}_{6}\right)$; participation in thematic weeks $\left(A_{7}\right)$; participation in the competitions "Spike", "Kangaroo", "Olympus", "Sunflower" / selfgovernment $\left(A_{8}\right)$; talented and creative $\left(A_{9}\right)$; library: events, rating, reading $\left(A_{10}\right)$; theater festival / total number of points of preliminary checks $\left(A_{11}\right)$; the success of the quarter $\left(A_{12}\right)$ (Table 1$)$. The best is the class with the highest score in the testing group.

At the same time, the methodological approach does not fully allow to examine the current situation in the class and identify possible changes in the rhythm of preparation of pupils compared to the neighboring classes of a particular group.

There are also questions about the objectivity of general evaluation results of the testing classes. This is due to the fact that two groups of indicators $A_{7}$ and $\mathrm{A}_{12}$ determine the future leading class. At the same time, there are questions arising on the expediency of using the groups of indicators $A_{2}, A_{3}, A_{4}, A_{5}, A_{6}, A_{11}$, because their impact is almost unremarkable, or has a single character.

It should be noticed that the most important task of any technique of evaluation is not only an incentive for the testing group (pupils, students, hearer, pedagogical and scientific and pedagogical staff) to maximize the results of activity, but also to ensure the maximization to the total of metrics, but not exclusively in two or three groups. 
Table 1

The evaluation results of each testing classes (IV quarter of 2018-2019)

\begin{tabular}{|c|c|c|c|c|c|c|c|c|c|c|c|c|c|c|}
\hline \multirow{2}{*}{ Class } & \multicolumn{12}{|c|}{ Groups of indicators } & \multirow{2}{*}{ Amount } & \multirow{2}{*}{ Place } \\
\hline & $A_{1}$ & $\mathrm{~A}_{2}$ & $\mathrm{~A}_{3}$ & $\mathrm{~A}_{4}$ & $\mathrm{~A}_{5}$ & $\mathrm{~A}_{6}$ & $\mathrm{~A}_{7}$ & $\mathrm{~A}_{8}$ & $\mathrm{~A}_{9}$ & $\mathrm{~A}_{10}$ & $A_{11}$ & $A_{12}$ & & \\
\hline $5 \mathrm{~A}$ & 40 & 0 & -9 & 0 & 0 & 40 & 17 & 7 & 40 & 5 & 0 & 61 & 201 & 4 \\
\hline $5 \mathrm{~B}$ & 40 & 0 & -6 & 0 & 3 & 0 & 48 & 20 & 3 & 48 & 0 & 77 & 233 & 2 \\
\hline $6 \mathrm{~A}$ & 40 & -4 & -4 & 0 & 4 & 0 & 59 & 14 & 33 & 23 & 0 & 80 & 245 & 1 \\
\hline $6 \mathrm{~B}$ & 40 & -12 & -4 & 0 & 5 & 0 & 0 & 25 & 50 & 5 & 0 & 50 & 159 & 6 \\
\hline $7 \mathrm{~A}$ & 40 & 0 & -6 & 0 & 5 & 30 & 31 & 23 & 15 & 17 & 0 & 48 & 203 & 3 \\
\hline $7 \mathrm{~B}$ & 40 & -6 & -13 & 0 & 2 & 0 & 8 & 22 & 9 & 4 & 0 & 35 & 101 & 7 \\
\hline $8 \mathrm{~A}$ & 40 & -12 & -10 & 0 & 0 & 0 & 5 & 19 & 0 & 0 & 0 & 26 & 68 & 8 \\
\hline $8 \mathrm{~B}$ & 40 & -2 & -14 & 0 & 0 & 0 & 22 & 18 & 40 & 17 & 0 & 42 & 163 & 5 \\
\hline
\end{tabular}

Source: authors' own work

Table 2

Comprehensive evaluation of the results of each class, give the possible level of oscillation within the analysis group

\begin{tabular}{|c|c|c|c|c|c|c|c|c|c|c|c|c|c|c|}
\hline \multirow{2}{*}{ Class } & \multicolumn{12}{|c|}{ Metrics group coefficients } & \multirow{2}{*}{ Amount } & \multirow{2}{*}{ Place } \\
\hline & $A_{1}$ & $\mathrm{~A}_{2}$ & $\mathrm{~A}_{3}$ & $\mathrm{~A}_{4}$ & $\mathrm{~A}_{5}$ & $\mathrm{~A}_{6}$ & $\mathrm{~A}_{7}$ & $\mathrm{~A}_{8}$ & $\mathrm{~A}_{9}$ & $A_{10}$ & $A_{11}$ & $A_{12}$ & & \\
\hline $5 \mathrm{~A}$ & 0 & 0 & 0.5 & 0 & 1 & 0 & 0.712 & 1 & 0.2 & 0.896 & 0 & 0.352 & 4.66 & 5 \\
\hline $5 \mathrm{~B}$ & 0 & 0 & 0.2 & 0 & 0.4 & 1 & 0.186 & 0.278 & 0.94 & 0 & 0 & 0.056 & 3.06 & 3 \\
\hline $6 \mathrm{~A}$ & 0 & 0.333 & 0 & 0 & 0.2 & 1 & 0 & 0.611 & 0.34 & 0.521 & 0 & 0 & 3.005 & 2 \\
\hline $6 \mathrm{~B}$ & 0 & 1 & 0 & 0 & 0 & 1 & 1 & 0 & 0 & 0.896 & 0 & 0.556 & 4.451 & 4 \\
\hline $7 \mathrm{~A}$ & 0 & 0 & 0.2 & 0 & 0 & 0.25 & 0.475 & 0.111 & 0.7 & 0.646 & 0 & 0.593 & 2.974 & 1 \\
\hline $7 \mathrm{~B}$ & 0 & 0.5 & 0.9 & 0 & 0.6 & 1 & 0.864 & 0.167 & 0.82 & 0.917 & 0 & 0.833 & 6.601 & 7 \\
\hline $8 \mathrm{~A}$ & 0 & 1 & 0.6 & 0 & 1 & 1 & 0.915 & 0.333 & 1 & 1 & 0 & 1 & 7.849 & 8 \\
\hline $8 \mathrm{~B}$ & 0 & 0.167 & 1 & 0 & 1 & 1 & 0.627 & 0.389 & 0.2 & 0.646 & 0 & 0.704 & 5.732 & 6 \\
\hline
\end{tabular}

Source: authors' own work

Using the formula 1 for the Table 2, the complex evaluation of the results of each class was carried out, considering the possible level of fluctuations in the middle of the testing group.

The results show that considering the level of oscillation in the middle of the testing groups, there were insignificant changes in the rating. However, for full use of the specified methodological approach in evaluation complex of the performance of each class should be further determined the proportion of the impact of each of the proposed groups of indicators on the overall performance indicator.

To evaluate the level of pedagogical professional qualifications of staff in terms of evaluating the results of their pupils' work it is necessary to determine, how the complex coefficient of the testing group during the course of recent reporting periods has changes.

Table 3 shows the results of a comprehensive appraisal of Grades 6-A (7-A) of the School of Liberal Arts (Kherson, Ukraine), based on three reporting periods.

The calculations show that maximizing the results of group work of pupils of the study class is observed in the fourth quarter of 2018-2019. Deterioration of the complex coefficient based on the results of the II quarter of 2019-2020 connected to mainly with the hormonal changes that occur at pupils of 12-13 years, and, as a result, their low motivation for self-improvement. Also worsening the level of the complex coefficient was the result of personnel changes that occurred in educational and pupil's educational activities of the educational

Table 3

Comprehensive appraisal of Grades 6-A (7-A) of the School of Liberal Arts (Kherson, Ukraine)

\begin{tabular}{|l|c|c|c|c|c|c|c|c|c|c|c|c|c|}
\hline \multirow{2}{*}{ Reporting periods } & \multicolumn{7}{|c|}{ Metrics group coefficients } & $\mathrm{A}_{12}$ & Amount \\
\cline { 2 - 22 } & $\mathrm{A}_{1}$ & $\mathrm{~A}_{2}$ & $\mathrm{~A}_{3}$ & $\mathrm{~A}_{4}$ & $\mathrm{~A}_{5}$ & $\mathrm{~A}_{6}$ & $\mathrm{~A}_{7}$ & $\mathrm{~A}_{8}$ & $\mathrm{~A}_{9}$ & $\mathrm{~A}_{10}$ & $\mathrm{~A}_{11}$ & $\mathrm{~A}_{12}$ \\
\hline $\begin{array}{l}\text { II quarter } 2018-2019(6-\mathrm{A}) \\
\text { of }\end{array}$ & 0 & 0 & 0 & 1 & 1 & 1 & 0 & 0 & 0.097 & 0.083 & 0 & 0 & 3.18 \\
\hline $\begin{array}{l}\text { IV quarter } \\
\text { of 2018-2019 (6-A) }\end{array}$ & 0 & 0.333 & 0 & 0 & 0.2 & 1 & 0 & 0.611 & 0.34 & 0.521 & 0 & 0 & 3.005 \\
\hline $\begin{array}{l}\text { II quarter } \\
\text { of 2019-2020 (7-A) }\end{array}$ & 0 & 0.125 & 0.667 & 0.333 & 1 & 0.938 & 0 & 0.25 & 0 & 0.842 & 0 & 0 & 4.155 \\
\hline
\end{tabular}

Source: authors' own work 
institution. However, the testing class continues to take first place in the overall grade of 5-8 forms of School of Liberal Arts. Therefore, to formulate more valid conclusions about it is advisable to carry out the results of the work of the form master for the results of the 2019-2020 academic year (adjusted for obliged online education in March-May 2020 in connection with COVID-19).

\section{Assessment of the personal level of professional competence of personnel}

To assess the personal level of professional competence of the form master of the School of Liberal Arts mentioned above, formulas 2-7 and the individual integral index of competitiveness were executed using the method taxonomic analysis with additional consideration of the specific influence of each factor to the integral indicator. To identify the key metrics, on which the realization of an objective assessment of the level of professional qualification of form master is possible, the working group was created, which included the leading experts of the industry (Kherson State University, School of Liberal Arts, Department of Economic and Regional Development of the Kherson Regional State Administration, Kherson Regional Intersectoral Trade Unions Council).

Table 4

Information space system for calculating the integral indicator of competitive-ness assessment

\begin{tabular}{|c|c|c|c|}
\hline \multirow{2}{*}{ Indicator } & \multicolumn{3}{|c|}{ Academic years } \\
\cline { 2 - 4 } & $2016-2017$ & $2017-2018$ & $2018-2019$ \\
\hline $\mathrm{B}_{1}$ & 15 & 18 & 20 \\
\hline $\mathrm{B}_{2}$ & 36 & 47 & 40 \\
\hline $\mathrm{B}_{3}$ & 44 & 55 & 59 \\
\hline $\mathrm{B}_{4}$ & 1.7 & 1.25 & 1.15 \\
\hline $\mathrm{B}_{5}$ & 12 & 18 & 15 \\
\hline $\mathrm{B}_{6}$ & 4 & 3 & 5 \\
\hline
\end{tabular}

Source: authors' own work

Table 6

Standardized values of indicators, intermediate values of point-standard, Eu-clidean distance and integral index

\begin{tabular}{|c|c|c|c|c|c|c|c|c|}
\hline \multirow{2}{*}{ Indicators } & \multirow{2}{*}{ Weight ratio } & \multicolumn{3}{|c|}{ Academic years } & \multirow{2}{*}{$\begin{array}{l}\text { Point of } \\
\text { reference }\end{array}$} & \multirow{2}{*}{$\overline{\mathrm{C}}_{0}$} & \multirow{2}{*}{$\mathrm{S}_{0}$} & \multirow{2}{*}{$\mathrm{C}_{0}$} \\
\hline & & $2016-2017$ & $2017-2018$ & $2018-2019$ & & & & \\
\hline $\mathrm{B}_{1}$ & 0.1 & -1.298 & 0.162 & 1.136 & 1.136 & & & \\
\hline $\mathrm{B}_{2}$ & 0.25 & -1.1 & 1.32 & -0.22 & 1.32 & & & \\
\hline $\mathrm{B}_{3}$ & 0.15 & -1.367 & 0.368 & 0.999 & 0.999 & & & \\
\hline $\mathrm{B}_{4}$ & 0.1 & 1.393 & -0.488 & -0.906 & 1.393 & & & \\
\hline $\mathrm{B}_{5}$ & 0.22 & -1.225 & 1.225 & 0 & 1.225 & & & \\
\hline $\mathrm{B}_{6}$ & 0.18 & 0 & -1.225 & 1.225 & 1.225 & & & \\
\hline Euclidean distance & & 2.118 & 1.260 & 1.205 & & 1.528 & 0.418 & 2.363 \\
\hline $\begin{array}{l}\text { Competitive Capacity } \\
\text { Integral indicator }\end{array}$ & & 0.1 & 0.47 & 0.49 & & & & \\
\hline
\end{tabular}

Source: authors' own work
Considering the level of competence of the involved experts, on the basis of the questionnaire conducted, the main indicators and the level of their significance when assessing the level of professional competence of the form master of School of Liberal Arts were identified, namely: average number of students, persons ( $\mathrm{B}_{1}$, significance $\left.-10 \%\right)$; hours of classroom workload, hours / week $\left(B_{2}, 25 \%\right)$; preparation of competition winners, points $\left(\mathrm{B}_{3}, 15 \%\right)$; publication of educational and methodical works, other sheets $\left(\mathrm{B}_{4}, 10 \%\right)$; individual consultations during off-hours, hours / week $\left(\mathrm{B}_{5}, 22 \%\right)$; organizational and administrative work, hours / week $\left(\mathrm{B}_{6}, 18 \%\right)$.

Table 4 presents the general system of information for calculation of the inte-gral index of competitiveness of the form master of testing class of the School of Liberal Arts.

Table 5 shows the calculation of the mean value and standard deviation for the group of indicators characterizing the level of competitiveness.

Standardized values of indicators, intermediate values of point-standard, Eu-clidean distance and integral indicator are shown in Table 6.

The obtained results of calculation of the integral index of the competitiveness of the form master of the School of Liberal Arts in Table 6 show that efficiency of his ore her work during 2017-2018 and 2018-2019 academic years significantly in-creased compared to the

Table 5

Calculation of mean and standard deviation

\begin{tabular}{|c|c|c|c|c|c|}
\hline \multirow{2}{*}{ Indicators } & \multicolumn{3}{|c|}{ Academic years } & \multirow{2}{*}{$\bar{A}$} & \multirow{2}{*}{$\delta$} \\
\cline { 2 - 4 } & $\begin{array}{c}2016- \\
2017\end{array}$ & $\begin{array}{c}2017- \\
2018\end{array}$ & $\begin{array}{c}2018- \\
2019\end{array}$ & & \\
\hline $\mathrm{B}_{1}$ & 15 & 18 & 20 & 17.67 & 2.055 \\
\hline $\mathrm{B}_{2}$ & 36 & 47 & 40 & 41.00 & 4.546 \\
\hline $\mathrm{B}_{3}$ & 44 & 55 & 59 & 52.67 & 6.342 \\
\hline $\mathrm{B}_{4}$ & 1.7 & 1.25 & 1.15 & 1.37 & 0.239 \\
\hline $\mathrm{B}_{5}$ & 12 & 18 & 15 & 15.00 & 2.449 \\
\hline $\mathrm{B}_{6}$ & 4 & 3 & 5 & 4.00 & 0.816 \\
\hline
\end{tabular}

Source: authors' own work 
2016-2017 academic year. Notation is also confirmed by the results of an earlier study on comprehensive evaluation of the results of work of 6-A form on the results of II and IV quarters of the 2018-2019 academic year. At the same time, there is a decrease of scientific and research activity of the subject, more than 60 hours for a week the specific form master spends on the implementation of the assigned functional responsibilities.

At the same time, the management of educational institutions should consider that essential increasing of workloads during working hours and out of work hours can lead to professional burnout of pedagogical worker and decrease the level of sat-isfaction with the fulfillment of functional duties and the desire to professional im-provement. This is partially confirmed by the decrease of efficiency of the testing class for the results of the II quarter 2019-2020 academic year by 1.15 conditional units, which may be associated with a decrease of educational workload, the duration of individual consultations in out of work-hours and increasing volume of organizational and administrative work for a form master.

The developed model of stimulation to professional improvement should pro-vide that the pedagogical staff will be provided payroll the cash back up to $50 \%$ if the planned targets of scientific and pedagogical activities in the out of work-hours are achieved. This will allow to view the load level of pedagogical staff in terms of reducing the amount of additional organizational and administrative work, and devote free time to relaxation and personal needs.

During the development of evaluation indicators and implementation of the appropriate model of staff incentives for professional development should also be taken into account that the permanent labor activity and the fulfillment of the set tasks will contribute to the formation of the justification of the chosen life and pedagogical activities in the personality, eliminating the negative thoughts and increasing levels of satisfaction and happiness from the chosen activity.

\section{Conclusions and recommendations for further research}

The results of the research indicate the need of improvement of the system of management of professional development of pedagogical and scientific and pedagogical workers, taking into account modern functioning aspects of educational institutions. Special attention should be emphasized on the development of scientific and methodological approaches to assessment of the level of professional qualification of employees in the testing group and in dynamics, determination of limit load and development of motivation model to professional improvement.

Rating the level of professional qualification of teaching staff it is proposed to take into account not only their own heritage to scientific and pedagogical industry, but also the results of their ward pupil's work. The above is particularly relevant in assessing the effectiveness of teaching staff who are concurrently form masters.

Given that the most important task of any evaluation methodology is not only the motivation of the testing group (pupils, students, hearer, teaching staff) to maximize the results, but also providing the specified maximization for the whole set of indicators is proposed to carry out the complex assessment of the results of the activity of the educational forms from the considering possible level of oscillation in the amidst of the testing group.

The management of educational institutions should consider that significant growth of workloads during working hours and out of work hours can lead to professional burnout of pedagogical worker and decrease the level of satisfaction with fulfillment of functional duties and desire to professional improve. This is partially confirmed by the decrease of performance activities of the testing class of School of Liberal Arts according to the results of the II quarter 2019-2020 academic year at 1.15 conventional unit of measure, that may be associated with a decrease of educational load, duration of individual consultations during out of work hours and increasing organizational and administrative work with a form master.

During the development of evaluation indicators and implementation of the appropriate model of staff stimulating to professional development should be taken into account that continuous labor activity and the fulfillment set of tasks will facilitate the formation in the personality of the validity of the chosen life and pedagogical activities, eliminating the negative thoughts and increasing the levels of satisfaction and happiness from chosen activity.

The mechanism of determining the coefficient of competence of experts in-volved in the evaluation of staff, taking into account their work experience, the scale of management activity, and the level of education, deserves further study. This will maximize the effectiveness of the rating and coordinate the efforts and resources of employees to improve defined and relevant for the educational institutions.

\section{References:}

Derkach, A. A., Zazykyn, V. H., \& Markova, A. K. (2000). Psychology of professional development: a textbook. Moscow: Nauka.

Edquist, C. (2004). Systems of Innovation - A Critical Review of the State of the Art. W: J. Fagerberg, D. Mowery, R. Nelson (red.), Handbook of Innovation. Oxford: Oxford University Press. 
Ivanová, E., \& Čepel, M. (2018). The Impact of Innovation Performance on the Competitiveness of the Visegrad 4 Conutries. Journal of Competitiveness, vol. 10(1), pp. 54-72. doi: 10.7441/joc.2018.01.04

Ko, H., \& Min, K. (2019). Determinants of social expenditures in post-socialist countries. Economics and Sociology, vol. 12(2), pp. 253-264. doi: 10.14254/2071-789X.2019/12-2/15

Lozovetska, V. T. (2015). Professional career of the individual in modern conditions: monograph. Kyiv: Institute of Vocational Education NAPS of Ukraine.

Maisiura, O. M. (2010). On the effectiveness of using personal time (to the issue of time management). Actual problems of economics, vol. 2, no. 104, pp. 196-200.

Makarenko, S., Kaplina, Y., \& Rybachok, S. (2019). Current Realities of Enterprise Personnel Training And Development. 9th International Youth Science Forum "Litteris et Artibus" \& 14th International Conference «Young Scientists Towards the Challenges of Modern Technology»: Materials. Lviv, Ukraine: Lviv Polytechnic National University.

Makarenko, S. M., \& Kazakova, T. S. (2019). Features of Management by Professional and Personal Development of Personnel: the Case of Ukraine. $3^{\text {rd }}$ International Conference on Economic Research: Proceedings Book (Full Texts - Abstracts) (24-25th October 2019 Alanya Alaaddin Keykubat University, Turkey).

Makarenko, S. M., Oliinyk, N. M., \& Kazakova, T. S. (2018). Improving the method approach to the rating evaluation of employees as professional career development. Baltic Journal of Economic Studies, vol. 4, no. 5, pp. $179-187$. doi: 10.30525/2256-0742/2018-4-5-179-187

Makarenko, S., Oliinyk, N., Danko, V., \& Kaplina, Y. (2020). Formation of an Innovative Competitiveness Management System of the Enterprise: On the Case of Ukraine's Healthcare. Journal of Economics and Management Sciences, vol. 3, no. 1, pp. 1-12. doi: 10.30560/jems.v3n1p1

Mokin B. I., \& Marymonchyk, Yu. V. (2004). Methodological basis of material incentives for effective operation of university personnel training of the teaching staff and the creation of high-quality scientific products. Visnyk VPI, vol. 2, pp. 26-31.

North, D. (1991). Institutions. Journal of Economic Perspectives, vol. 5(1), pp. 97-112. doi: 10.1257/jep.5.1.97

Obmok O. H. (2014). Accounting of the rating assessment results of the activities of Academic staff. Visnyk ahrarnoi nauky Prychornomoria, vol. 3, no. 80, pp. 83-90.

Redko, S., \& Panchenko, A. (2015). Research of pedagogical workers' motivation sources as factors of success of secondary school. The pedagogical process: theory and practice, vol. 3-4(48-49), pp. 29-34.

Tyukhtenko, N. A., \& Makarenko, S. M. (2016). Economic and mathematic models for staff planning at enterprises of all ownership forms. Actual problems of economics, vol. 1, no. 175, pp. 435-442.

Zachosova, N. (2019). Innovative approach in the estimatology of financial institutions economic security: possibilities of use in management and regulatory activity within the means of provision of the state financial security. Baltic Journal of Economic Studies, vol. 5, no. 2, pp. 45-56. doi: 10.30525/2256-0742/2019-5-2-45-56 